\title{
Advances in Higher Educational Resource SHARING AND CLOUd SERVICES FOR KSA
}

\author{
Bariah Aljebreen ${ }^{1}$, Prof. Ajantha Dahanayake ${ }^{2}$ and Liyakathunisa Syed ${ }^{3}$ \\ ${ }^{1}$ Researcher, Department of Software Engineering, Prince Sultan University, Riyadh, \\ Kingdom of Saudi Arabia (KSA) \\ ${ }^{2}$ Professor, Department of Software Engineering, Prince Sultan University, Riyadh, \\ Kingdom of Saudi Arabia (KSA) \\ ${ }^{3}$ Assistant Professor, Department of Software Engineering, Prince Sultan University, \\ Riyadh, Kingdom of Saudi Arabia (KSA)
}

\begin{abstract}
Cloud represents an important change in the way information technology is used. Cloud makes it possible to access work anywhere anytime and to share it with anyone [1]. It is changing the way people communicate, work and learn [2]. In this changing environment, it is important to think about the opportunities and risks of using the cloud in the education field, and the lessons we can learn from the previous uses of this technology in the education field. In order to gain the benefits of the cloud to be used in educational system in KSA, a comprehensive study on scientific literatures in this paper. This paper also presents the significant information such as the findings, the case studies, related frameworks and supporting also the tools associated to the migration of organizational resources to cloud.
\end{abstract}

\section{KEYWORDS}

Cloud Computing, Educational cloud, KSA, Resource Sharing.

\section{INTRODUCTION}

Cloud Computing is evolving as a key technology for sharing resources. It can be defined as a shift from local computing offerings to external cloud provider [3]. The benefits of cloud are documented and defined by Badger et al. [3]. The document presents the major classes of cloud technology and provides guidelines for organizations on how to define the related advantages and risks of migration to cloud computing. Moreover, the document introduces different technologies and structures to adapt to the various requirements of organizations. The authors demonstrated that the features to consider for cloud are the following:

1. The Deployment Models represent the various cloud deployment methods that are private or hosted by the cloud customer and shared among a limited number of trusted partners, and which use a third party service for public accessibility.

2. Service Models describe the types of services provided by clouds, which are: entree to software such as email or office automation tools, called Software as a Service (SaaS); toolkit to let the customer organization build and operate their own software, known as Platform as a Service $(\mathrm{PaaS})$; network access to traditional computing resources such as processing power and storage, called Infrastructure as a Service (IaaS).

3. Economic Considerations describe the method of paying for cloud services. Users are charged while using a service. This method provides elasticity that avoids unnecessary costs from over-provisioning. 
4. Operational Characteristics are concerned with the appropriateness of the applications to be hosted on cloud. Applications that can be segmented into small independent parts are more appropriate to migrate to cloud.

5. Service Level Agreements (SLAs) list the responsibilities of the customer organization as well as the cloud service provider's responsibilities before migrating to cloud.

6. Security is concerned with the traditional computer and network security issues. These issues include data confidentiality, data integrity, and system availability.

To integrate multiple dimensions and to produce different analysis to understanding relationships among the findings of the literature framework of cloud migration, most of the previous works in this field are studied and summarized [4]. The findings include an authentic method to segment the application and then migrate it to the cloud. After that, according to the elasticity offered by the cloud provider, the suitable providers are chosen.

From an organizations' prospective, there are factors that need to be considered in making the decision of migrating to cloud computing. Avram [5] analysed costs, return on investment, performances, security, and integration with the existing IT infrastructure and existing software. The study considered the company size and business specialization to identify the proper type of cloud computing solution. The results show that the business processes must be evaluated to identify the risks and advantages of cloud migration. The author suggested that small and midsized processes can merge to cloud easily as they have less complex processes. In addition, the outcome of the cloud migration has two features; utility and guarantee. The organizations planning for cloud migration must define their economic objectives related to four elements; namely, financial, customer, internal and learning-development, and then recognize the way cloud services can tolerate these aims [5]. The strengths and drawbacks of cloud computing for businesses and academics are proposed by Marston et al. [6]. They outline some of the basic issues facing governmental agencies intending to migrate to cloud. They discuss several points of concern, which are cloud service pricing mechanism; ideal risk transfer and SLA contract; partnership 3rd party relations; the optimal set of guidelines to perform the migration to a private or public cloud; finding the best solutions of cloud; formulating Information Systems (IS) policy across the practice of multiple cloud providers; the ideal set of guidelines to decide the types of applications to migrate to cloud; the IT auditing strategies, security issues and international regulations, and assessing the risk involved in migrating to cloud computing [6]. The cloud solution proposed by Jun et al. [7] can provide an effective decision support system. It can decrease the capital costs and provide viable services. Performance analysis can be done to prove the effectiveness of cloud migration. Further Sodhi et al. [8] proposes that the Private Cloud is superior to the Public Cloud for most Quality of Attributes (QAs).

\section{Cloud Migration}

Cloud can be defined as rent entree to fully functioning applications, software development, and deployment settings, with an infrastructure that provides network- data storage and data processing [3]. However, by performing unbroken management practices, security updates and response issues are improved. There are several migration types to distribute applications [9]. An application may be segmented physically into different components or logically according to functionality. Another point of view is whether the applications migrate partially or completely.

Therefore, there are four migration types [9].

Type 1: partial migration by replacing one or more components of the application to the cloud. It is the minimum risk migration type.

Type 2: migrate a component of the application functionality to the cloud such as a group of components from one application layer. 
Type3: migrate the whole application to the cloud based on the virtualization of cloud. Type 4: migrate the application associated with the data layer and business logic layer.

Park et al. [10] uses a longitudinal design to get data from undergraduate students at two universities in Korea in the context of IT switching to Google Apps settings. The results show two important ideas. The first is a strong positive attitude towards cloud migration, as well as a moderate attitude that overcome the negative effect of expected costs. The second one is that having existing software is difficult to be imitated and replaced by alternatives such as cloud applications. Finally, personal productivity software such as Microsoft Office is widely available and can provide help to users and organizations as compared to free cloud services such as Google Applications [10]. The benefits of using Cloud, as well as the disadvantages of implementing it are illustrated by Sultan [11]. A case study is made in the University of Westminster to get the results. First, the advantages include decrease in cost of buying and installing hardware and software, usage of power, and carbon footprint. Another advantage is delivering a diversity of computing services. Disadvantages of using cloud are security, reliability, and portability [11]. Khajeh-Hosseini et al. [12] made a case study that illustrates the advantages and challenges associated with oil and gas industry companies' migration to cloud. The case study examines an in-house data center migration to Amazon EC2. It also made the cost instability in terms of cloud-usage and data transfer costs, with a focus on systems infrastructure costs only. The findings concluded that cloud is a cheaper solution compared to purchasing, hosting, and maintaining IT systems infrastructure in-house. Moreover, cloud reduces support and maintenance problems. Concerning the drawbacks of cloud migration, they concluded that there is reduction in customer satisfaction because of the decreased overall service quality due to moving of control to third parties who are the cloud service providers. Concerning the employees, there is a declined job satisfaction due to changes in the nature of work [12]. A step-by-step process to support commercial medical application migration to public cloud is proposed by Beserra.et.al [13]. The authors created template profiles illustrating the organization; they aimed at legacy application and the applicant cloud providers. Then these pieces of information pass through a cross-analysis to identify and resolve critical limitations that may delay migration to the cloud. The best practices of service migration design, as well as how these patterns should be applied during the migration of a service-based application or multiples thereof are presented by Fehling.et.al. [14]. The case study was conducted for a web-application migration from Amazon Web Services to the T-Systems cloud offering Dynamic Services for Infrastructure (DSI). The findings illustrated that service-based applications have specific architectural characteristics that make them perfect to cloud migrations. They defined migration patterns [14]. Zhou et al. [15] discussed existing problems of public education resource. They propose an application of a cloud services model according to a case study made in China concerning the country's public education. Finally, they developed the Public Education Resource Cloud Services (PERCS). To identify PERCS, difficulties of resource sharing must be studied first. Then, the new technologies that can be implemented are studied. Finally, the mission of public education is altered from the resources practise to providing services in the public educational development.

Ming-ming et al. [16] made a case study to examine the distance-learning in China. According to the existing problems, the authors proposed the architecture of advantages provided by cloud. The architecture includes platform services, software services, teaching information resources, improvement on using the resources, and reduction in the system building costs. Cloud is not only useful for IT solutions, but can also be used to support our daily life affairs. Li et.al. [17] presented a data integration approach based on three environmental Sensors, Model Networks, and Australian Water Availability Project database. The integration approach is made to estimate ground water balance and average water availability. The Commonwealth Scientific and Industrial Research Organisation (CSIRO) sensor cloud infrastructure has been used widely to process big data integration and the machine learning based decision support system. Another use of cloud is a new Decision Support Systems (DSS) solution design proposed by Miah.et.al. [18]. 
The solution is an intelligent technique that decision makers of the Australian Road Safety can obtain on-demand to monitor records regarding the behavior of temporary license holding drivers. The structures of the trusted cloud framework guarantee the integrity and confidentiality of the out-sourced computations through clouding [18]. Environmental decision support systems (EDSS) module was developed by Sun [19]. It is a traditional client-server application hosted by Google Drive, which is a cloud service provider. EDSS provides basic visual analytics structures that increase the combined decision-making experience while radically reducing the cost of Watershed Management [19]. Sultan [20] made another study on healthcare environment. He proposed that using cloud in health facilities provides openings for cost-savings and inventive solutions. A small case study titled "proof of concept" was implemented in a London hospital. In order to classify the numerous applications of cloud technologies in educational institutions, Tan et.al. [21] used a case study. The findings are the common success factors. However, this study spans for years and the results are not yet concluded.

\section{Cloud Frameworks AND SuPPORTINg TOOLS}

This section presents the various cloud frameworks and supporting tools as discussed in scientific literature.

A Decision Support System (DSS) is proposed by Song [9] for application in migration to the cloud. The system provides user-friendly interface. It enables the users to enter the system, and then the system displays the answer of which cloud service providers can host their business based on the entered requirements. Xiu [22] created a DSS that contains a database, user interface and data handler. The database is called Cloud Provider Knowledge Base, and it is hosted by two cloud providers, Google and Windows Azure. Each provider contains a set of cloud offerings that has various performance features and configurations. The data handler contains two main functions, offerings matcher and costs calculator. The first function is applied by comparing between user's requirements and the data in the database. The second function is achieved by calculating the pricing formula with certain values. A user is free to choose his favourite data center location and usage pattern with a certain rate for a certain period. The results of the users' search are presented easily after he enters his requirements ranked according to suitability [22]. A list of security and privacy features are presented by Kalloniatisa et al. [23] to address and handle the threats of cloud areas, such as Isolation, Availability, and Transparency. Many organizations are adopting cloud. Consequently, many researches are focusing on selecting the best cloud service provider according to certain conditions. To evaluate the benefits of purchasing compared to renting storage from a cloud a model is presented by Brisken et al. [24] for calculating a reasonable approximation of the possible outcomes. The investigation is made on Serial Advanced Technology Attachment (SATA) disk drives. The main contribution here is the understanding of the real cost of migrating assets to cloud services to guide stakeholders on taking rational decisions [24].

The service selection technique has been applied by Zhang [25] by using Structured Query Language (SQL) and regular expressions to minimize the negative side and strengthen restrains of cloud migration. This way, an improved cloud selection comparison Web system is created and it is illustrated in Figure 7. The services used for the selection are storage, and price_storage_requests, provider, compute, network, regional_price. Regional price include other components [25]. 


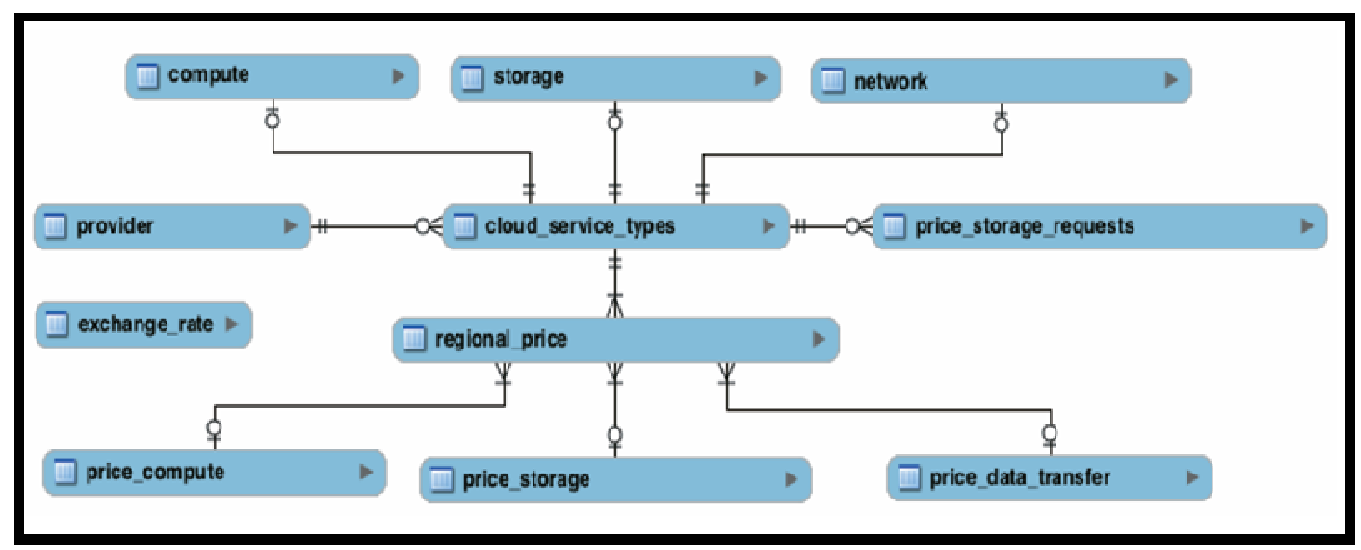

Figure 1: Serviced and relationships in cloud implementation [25]

Previous studies failed to provide a systematic method that enables selection of a suitable cloud service provider based on requirements as well as security and privacy requirements. Mouratidisa et al. [26] proposed a framework, according to the organisational context, identified goals, actors, tasks, resources, and plans. The framework can analyse security and privacy constraints, goals, and threats related to cloud migration [26]. Andrikopoulos et al. [4] proposed a three-tiered architecture to select an appropriate cloud service provider. They investigate both cost calculation and offerings' matching. They suggest that the architecture may include end users, a knowledge base of cloud service providers and their offerings, and a back-end that provides selection and cost calculation logic. The results of the analysis are ranked. According to the authors, more study is needed to cover more concerns such as elasticity strategy, Quality of Service (QoS) characteristics, performance forecast, and security concerns [4]. A conceptual framework of service-oriented decision support systems for cloud migration is presented by Demirkan et al. [27]. Organizations intending to migrate to cloud must be careful with the service level, quality of service, the cost and the duration of delivered services. The proposed framework focuses on reduction in unit service costs due to scale, scope, and speed. Scale indicates reduction due to increase in operational size. Scope indicates reduction due to increase in the number of developed and provided services. Speed defines the reduction due to the increase in number of services put through the supply/demand chain [27].

To evaluate the adoption of cloud, a Cloud Adoption Toolkit is discussed by Khajeh-Hosseini et al. [28]. Using the toolkit, the purpose of the organizations is matched with the appropriate techniques. The Cloud Adoption Toolkit includes analysis for Energy Consumption, Technology Suitability, Stakeholder Impact, Responsibility Modeling, and Cost Modeling. The findings concluded that it is difficult to generalize the results on every organization [28]. Moreover, two tools for modeling cloud migration as IaaS are presented by Khajeh-Hosseini et al. [29]. The first tool is for IT architects. They define their applications data, and infrastructure requirements, as well as their resource usage forms. Then, the tool is used to compare the cost of different cloud providers. The second tool is a spreadsheet that outlines the outcome and challenges of using IaaS clouds from an enterprise standpoint. This second tool is considered a starting point for risk assessment. These tools need more investigation for longitudinal data. Juan-Verdejo [30] presented a framework of the decision-making process automation of cloud migration based on the advantages and disadvantages of migration related to enterprise policies, data sensibility, performance, cost savings from migration, dynamic performance, bottlenecks, data flows between application components, and the spread and variability of users. The results showed that migration can decrease SLA (Service Level-Agreement). However, it can handle issues such as higher reliability due to the higher level of replication, peaks in workload, existence of multiple 
fault domains, and the deployment of the application on multiple clouds [30]. Cloud Genius framework addresses cloud challenges and automates the decision-making process for Web server migration to the cloud. It used Analytic Hierarchy Process to perform automation of the selection of cloud provider based on QoS parameters [31]. A mathematical entity called Stochastic Point Cloud (SPC) is capable of handling the computational complexity when there is lack of data or when there is disagreement of include/exclude a section of data from past observation. SPC provides an opportunity to visually understand the cloud decision process. In addition, it increases the trustworthiness and transparency of a decision making process. This study used the normaldistribution-driven SPC and took place in Abu Dhabi Emirate of United Arab Emirates [32].

Companies must identify their fitting migration to the Cloud Architecture Model. They must analyze several features of their own business, as well as pre-existing IT resources. A general Suitability Index model is developed to consider various incorporeal impacts of cloud. With the appropriateness index modified to the companies' needs, they can easily get a clue to what kind of migration to adopt. The developed model considered a large number of factors [33]. Oracle corporation developed Cloud Candidate Selection Tool (CCST), which is an evaluation framework to help IT organizations define which applications, services, components, etc. are appropriate for placement to a cloud, either private or public. The analysis production from the CCST provides a visual symbol of the current architectural evaluated components with respect to deployment to a cloud environment. Numerous examples of patterns that are commonly realised when using the tool are presented [34]. Mithani et al. [35] made a model for dynamic resource allocation in a real time manner with reduction of cost. Using this model, organizations can move to a public cloud environment with the most fit for the business service workloads without redesigning the applications or changing their business logic. The model assesses the public cloud providers based on features and limitations. A visual presentation of the Systems, Applications and Products (SAP) in Data Processing applications enables easy communication with a tool to estimate the cost of cloud hosting. One of the largest and famous organizations has moved its services to the cloud. SAP AG is a huge software corporation that moved its services to the cloud. After this important step, companies that are using SAP AG applications and products started to think about the reduction of cost, if they moved to cloud. A decision support tool to help companies to enlist the costs involved using the existing IT systems and accordingly the cost of the cloud hosting, will be calculated. The tool offers the expenses involved for both storage locations to the user and shows a clear influence of moving an application [36].

In the next section, off the shelf educational cloud applications like Amazon, Microsoft, Google, and IBM Cloud Services are presented.

\section{Off The Shelf Educational Cloud Applications}

Cloud can provide suitable and sufficient resources to be used with ease. In this section, the existing Educational Cloud applications are discussed.

\subsection{Amazon Education Cloud}

Amazon Education Cloud provides Amazon Web Services (AWS). AWS provides scalable, accessible, reliable, and flexible solutions for schools and universities. Furthermore, AWS can be used as (IaaS). This way, AWS provides basic computing competence of virtual machines to provide high performance, reliable networking as well as redundant storage. Examples of Universities that have moved to AWS are University of San Francisco, University of California at Berkeley, and Harvard Medical School [37]. 


\subsection{Microsoft Education Cloud}

Microsoft Education Cloud Computing (MECC) is a giant model of resources that enables the students and researcher to migrate to the cloud. It enables the researchers to get rid of tasks of infrastructure administration. In addition, other tasks are easy to do over its Web-based services. All MECC services offer great financial flexibility for educational institutions with low costs of development, scalability, operation and migration. MECC offer a service called Microsoft Live@edu, which includes many services such as On-Line Document Sharing, Enterprise Class Tools, Cloud Based E-Mail, Alumni Communication, and On-Line Document Storage [1]. Microsoft's cloud as (IaaS) is called Windows Azure. Windows Azure is an operating system that allows the higher educational institutions to run operating system applications and store data by Microsoft server [1]. Actually, Microsoft is offering a wide range of applications for education to fulfill various educational tasks such as Communication and Collaboration, Web Portals, Device Management, Educational Analytics (for Schools only), Financial management, Institutional Effectiveness(for Higher Education only), relationship management, and server and cloud platform for IT efficiency. Such variations of services enable full or partial immigration to cloud for educational institutions [38].

\subsection{Google Applications for Educational Cloud}

Google App Education (GAE) is a cloud based Web application operated on the Google Infrastructure. It enables educational users of different levels such as faculty, researchers or students to use Web applications with no cost. The users can share ideas more quickly, do tasks effectively, have competent communication, and share tools. Google Apps Education includes a collection of Web-based messaging tools such as Google Talk, Google Mail, Google Sites, Google Video, and Google Calendar, as well as Google Docs Package for free [1].

\subsubsection{IBM Cloud Services to Education}

IBM SmartCloud for Education introduces cloud services to distribute computer lab contents, programs, and services to the educational entities without the need for advanced IT proficiency. It offers self-service reservation such as student achievement, graduation rates, scholarship funding, and demands for IT resources for research that can be accessed anytime from anywhere [39].

\section{EDUCATIONAL CLOUD}

In this area, there is an attitude to improve the educational systems and services in universities and academic institutes. Consequently, there is a huge competition among the universities on the quality of education they provide. However, the educational institutions face a stressing challenge of funding [2]. Cloud Education can be a solution to improve educational services. For this reason, Cenka et al. [40] made a study that consists of several phases that include recognizing problems and needs, defining the services, design for using Cloud in Education, application, testing, and assessment.

The findings conclude:

- Services needed are e-Library, e-Course, e-Academic, e-Learning, and e-Lab.

- The data to manage include library collections, learning materials, scientific publications, student IDs, professor's profile, and education profile.

- Infrastructure services needed are storage. 


\section{Benefits of cloud in education are:}

- All the educational related knowledge is accessed via devices such as computers, tablet computers, and mobile phones.

- Using this method of education reduces the time and cost.

- Accessibility is gained by using several types of devices.

- Knowledge sharing is encouraged.

The only point of concern is to study the security aspect of such migration. Educational organizations that have limited budgets and a number of challenges may consider cloud migration for their IT tasks. This method of using cloud is called "Education and Learning as a Service" (ELaaS). ELaaS is a hybrid method that can be implemented including cloud or non-cloud based solutions [41]. Cloud Cube Model (CCM) is a cloud computing formation model. CCM is based on four principles represented by a cube where each opposite face is measuring the same criteria. Hence, two opposite faces are left blank. Consequently, CCM is unbalanced. To reserve the symmetry of the cube, Complete Cloud Formations $(C 3 F)$ is made. $\mathrm{C} 3 \mathrm{~F}$ is a new formation model based on CCM. It has three main principles that reflect two values; each representing all of the sides of the cube. The three principles are Physical Location and Management, Technology Ownership, and Architectural Mindset. For the physical location and management, it has three values namely Internal/In-sourced, Internal/Out-sourced and External/Out-sourced. Internal/Insourced means that the application is within the organization's physical boundary under the control of the organization's own staff. Internal/Out-sourced means that the application is within the organization's physical boundary, but under the control of a 3rd-party. Finally, External/Outsourced means that the application is out of the organization's physical boundary and it is controlled by a third party. For the technology ownership, it has two values namely Proprietary or Open. Proprietary means that the cloud service provider is controlling and administering the application. Open means that the cloud providers are using open technologies. This means that the organization is not constrained to selected parties. Architectural Mindset can be parameterised or De-parameterised. Parameterised means (IaaS) and (PaaS). De-parameterised means (SaaS). Each class is then mapped into the appropriate position in the $\mathrm{C} 3 \mathrm{~F}$, creating ELaaS Quadrant. Then, the IT missions are categorized into two criteria; mission criticality and sensitivity. In addition, each one has the value of Low or High. Finally, each category of the IT missions is charted into the suitable position in the $\mathrm{C} 3 \mathrm{~F}$. The resulting quadrant is called ELaaS Quadrant [41].

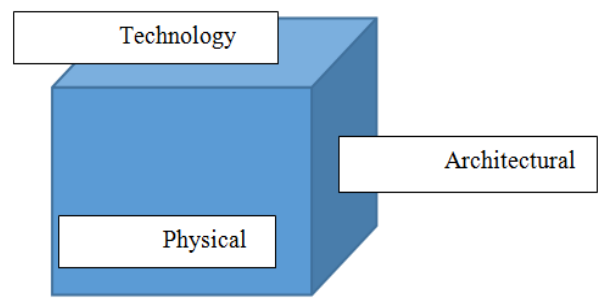

Figure 2: ELaaS Quadrant [41]

Business Intelligence (BI) applications provided by the cloud providers can enhance the business and educational functions of the educational entities. Saas business intelligence enables deploying programs faster and analysing the data more swiftly [42]. Akhmetov et al. [42] proposed a quantitative evaluation model of impact on knowledge of the students, as well as the impact of teachers by using the fuzzy logic. The proposed model helps to take decisions about the 
quality of the offered subject. Accordingly, the university manager can make decisions on refining the quality of the different services offered.

\section{Educational Clouds in KSA}

Most of the organizations across the world are constantly developing and deploying IT-based solutions to improve their services and increase net outcome. Moreover, such IT solutions help various sponsors with better communication and decision support. IT solutions adopt modern information technologies (IT) such as the internet and wireless communication technologies. To get the maximum benefits from the IT solutions, they must be appropriate to the tasks of the business processes [15]. In the education field, students are always developing and improving their skills. Consequently, IT infrastructure must coop these swift advancements. Using the latest technology of cloud as educational infrastructure enables the educational entities to manage the broad educational processes. Cloud architecture implementation offers reduction in expenses, elasticity, scalability, and accessibility [15].

In this section, we first explain the current situation with respect to KSA's higher educational system and the position of educational cloud within this context. After that, the common success factors of Educational Cloud implementations are highlighted according to the literature review and the related Saudi researches. Finally, the gaps that need more investigation are covered.

\subsection{KSA Higher Educational System}

This section discusses the general information about the ministry of higher education as well as the ministry responsibilities.

\subsubsection{Ministry of Higher Education of KSA}

Saudi Arabia's education system has gone through an amazing revolution. In 1932, the Kingdom was established and education was mostly offered to wealthy families living in the major cities [43]. In the early 1970s, Saudi Arabia began focusing on higher education. Later on in 1975, the Ministry of Higher Education was established. By 2015, Saudi Arabia's education system embraces 25 public and 27 private universities. The system has become free to all citizens and includes education, books, and health services. However, the focus on studying of Islam remains the core [43]. About 1 million students are enrolled at Saudi universities and colleges. Moreover, the Saudi government offers specialized graduate and postgraduate degrees abroad to thousands of Saudi students [43]. In 2015, Prince Khalid Al-Faisal, the Minister of Education has approved a number of educational projects at a cost of SR319 million ( $\$ 85$ million) across the Kingdom. The projects include more than 20 schools and educational complexes and construction of sports halls [43].

\subsubsection{The Responsibilities of the Ministry of Higher Education of KSA}

- It affords support and services for the kingdom's universities and colleges.

- It is responsible for the coordination, supervision, and follow-up of post-secondary programs, as well as linking with the national development programs in different fields.

- It also delivers the necessary technical and administrative manpower to the various social sectors.

- It manages scholarships of Saudi students studying abroad.

- It coordinates international inter-university relations [44]. 


\subsection{Educational Cloud in KSA Higher Educational System}

There are almost no researches about Educational Cloud implementation in KSA and the Arabian countries. In the following section, we will illustrate some researches that can pave the way for implementing Educational Cloud in KSA. In 2009, to have a better understanding and to measure students' perceptions towards the effectiveness of mobile learning in Saudi Arabia, an investigation of 186 undergraduate female students at King Saud University was done [45]. It illustrates their attitude towards the use of mobile technology in education. The author defines a way on how this technology can be used optimally to improve student performance. The results clearly indicate that offering mobile learning could improve acquiring of B.A and M.D. students, by improving their teaching and learning processes. The major advantage is that mobile learning can take place anywhere and anytime. Moreover, using the mobile learning system improves communication among the students who are enrolled in the open, as well as the distance learning [45].

Alshumaimeri Y. et al. [46] conducted a case study to examine the current availability of ICT facilities (Information Communications Technology) to teachers of English as a foreign language. The purpose of this study is to examine the current availability of ICT facilities to teachers of English as a foreign language. A questionnaire is administered in order to ascertain the differences between teachers in their report of available ICT resources and their use of such resources. The findings indicate that the most frequently utilized resources include the use of the internet to review updates in teaching English. However, teachers report feeling as if they did not have adequate experience in using the computer and did not feel the education directorate provides adequate support, equipment, and learning opportunities for English language teachers in ICT. Factors found to have an impact on whether or not computers are being integrated into classroom instruction include the use of a home PC, access to computer labs in the school, and computer training. In conclusion, the study suggests that greater availability of new teaching technologies such as computer labs and training programs will better ensure the integration of ICT resources into the lesson plans of EFL teachers [46]. In 2011, a mobile learning framework was created and validated by interviews using a qualitative method in Saudi Arabia [47]. 


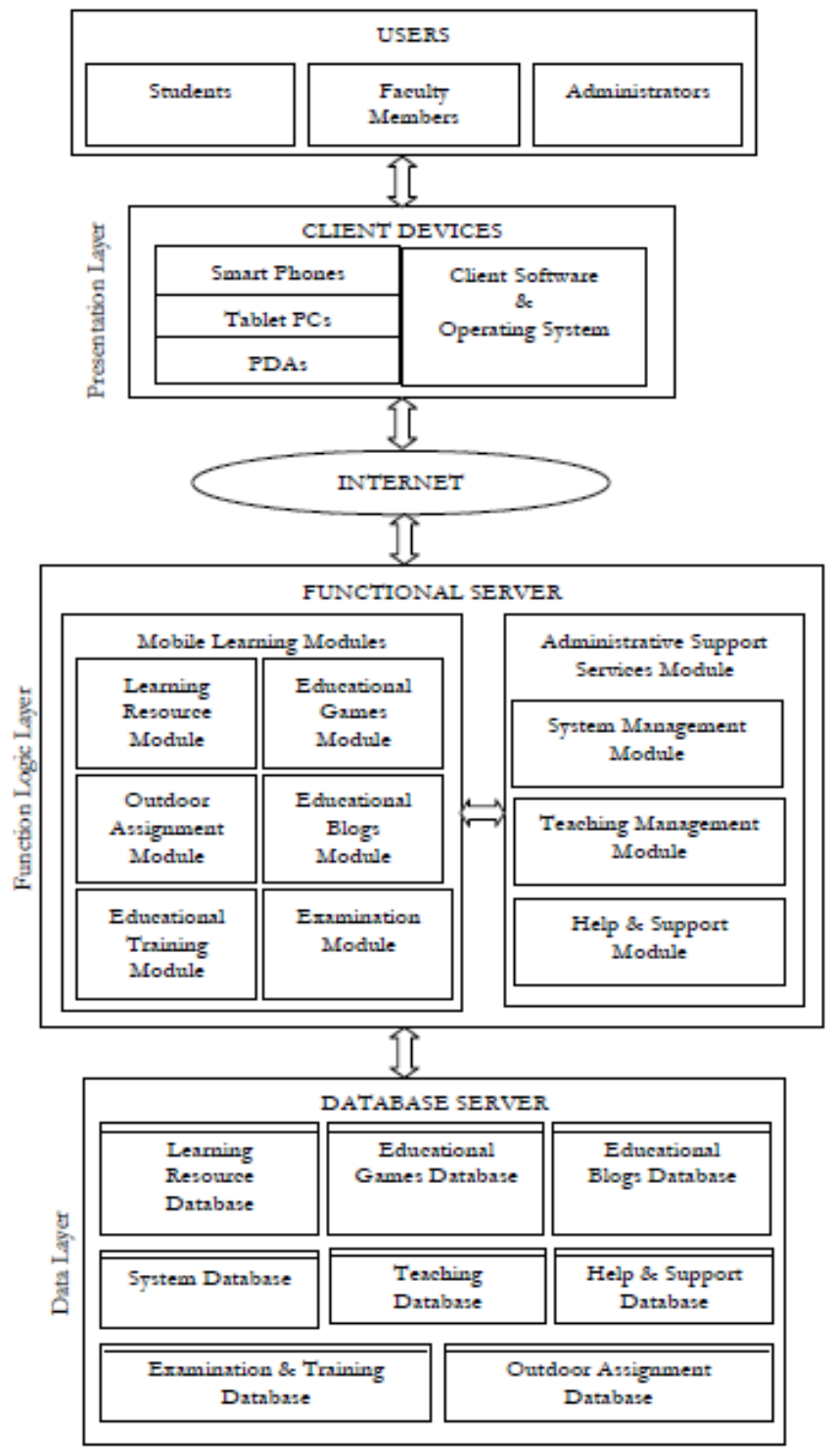

Figure 3: Suggested Mobile Learning framework 2011 [47]

Suggestions of the framework include:

i. Separation of functioning modules into two groups, which are mobile learning module and administrative support service module.

ii. Introduction of educational blog and educational games module.

iii. Use of distributed databases. [47].

In 2012, another study investigated the same subject matter that is to examine acceptance in Mobile Learning (M-Learning), but this time to serve in the development of distance learning for higher education [48]. The results from the statistical analysis show that the acceptance level of students on m-Learning is high level. This study adds an examination of the factors that promoted the behavioral intention to use m-Learning. Although, more than half of the students are not used to m-Learning, they had a good attitude towards it. Therefore, the university 
administration should focus on the design of m-Learning systems. Good insight and university policy are two major aspects that lead to success in m-Learning system [48].

Moreover, in 2011, a complete hierarchical framework that measures and categorizes all criteria affecting the developments and deployments of cost-effective M-Learning was presented. The framework is easily used and it is illustrated below [49].

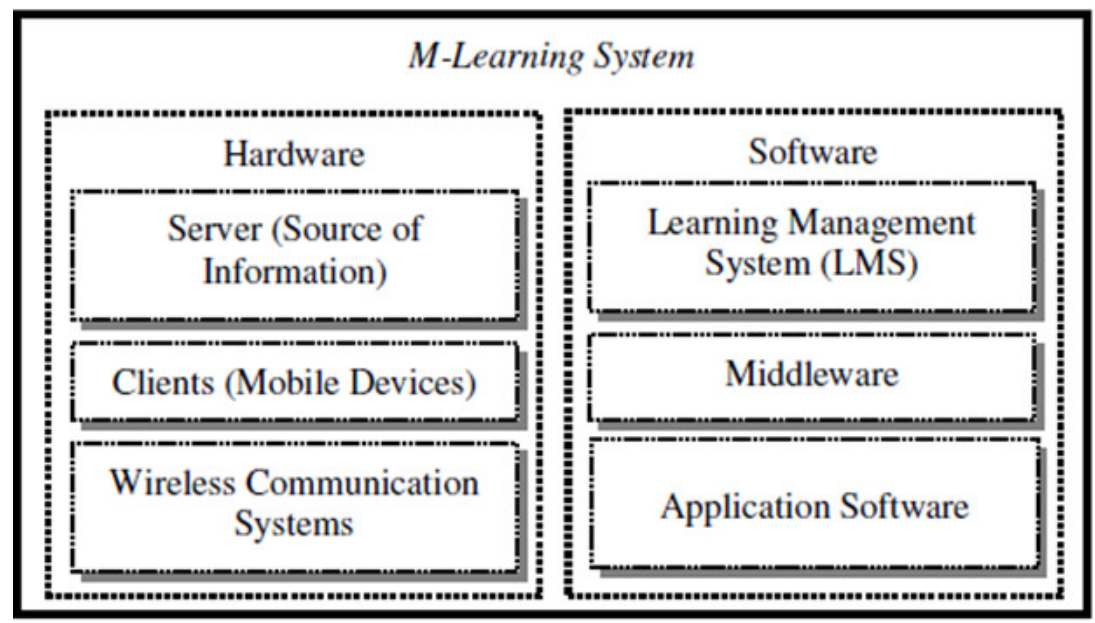

Figure 4: M-Learning System [49]

Furthermore, due to the hierarchical structure of the framework, Analytic Hierarchy Process (AHP) technique is used to quantitatively approximate the success factors of the system. The framework is illustrated below [Figure10].

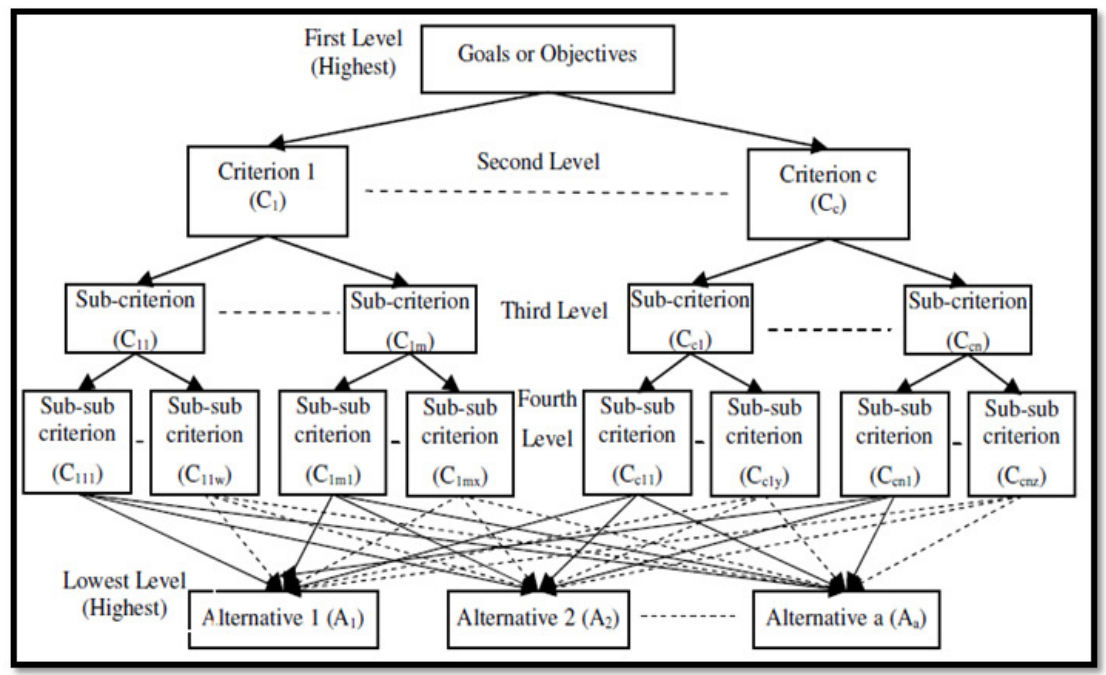

Figure 5: Standard Hierarchical Framework [49]

The proposed success factors are:

1. A user-friendly Graphical User Interface (GUI).

2. Using object-oriented methodologies for easy modifications.

3. Quantitatively evaluate the success factors. 
4. Include enough help

5. Demand little resources in terms of speed and memory.

6 . Be a new project or migrate with an existing one.

7. Select the evaluation technique (AHP, FAHP, and FEA)

8. Enter the number of criteria, suggested by the framework, to be measured

9. Define all the sub criteria

10. Perform calculation to estimate the global weight for each criterion

11. All input and computed parameters are stored in a database for further processing any time later [50].

\section{RESULTS}

Educational Cloud Computing is a promising technology that encourages learning with reduced cost. It is also accessible all the time from anywhere and is devoted to the idea of life-longlearning. Adopting Educational Cloud Computing technology needs to be studied in order to define its value and its mechanism of implementation [41].

Current higher educational settings are traditional in nature and are often unable to face the demand for rapid changes in technologies in an interactive learning environment [51]. The same is true for e-learning which appears to have numerous limitations starting from the use of local surroundings. In addition, infrastructure limitations often force institutions to avoid using multimedia contents in synchronized form due to the cost involved. Because of these and many other limitations, institutions often eliminate the use of sophisticated educational platforms [51].

This paper aims to understand the benefits of implementing educational Cloud Computing in higher education system especially in KSA. There is a need to create a framework that identifies the requirements which will justify the implementation and assisted migration of educational Cloud Computing for higher education institutions in KSA. In addition, when creating this type of framework the educational, cultural and economic related problems should be taken into consideration.

\section{Conclusions}

This paper presents a detail overview of cloud and its technologies, as well as the features that need to be considered for cloud deployment. An exhaustive literature survey on educational cloud is performed. A comprehensive literature survey on cloud migration is also provided in this paper. Various cloud framework and supporting tools for cloud are also discussed, and the off the shelf cloud application are also presented. Finally, the educational cloud in the Kingdom of Saudi Arabia is discussed.

\section{REFERENCES}

[1] F. Alshwaier, A. Alshuwaier and A. Areshey, "Applications of cloud computing in education," in IEEE $8^{\text {th }}$ International Conference on Computing and Networking Technology (ICCNT), Gueongju, 2012, pp. 26-33.

[2] B. Hirsch and J. Ng, ,"Education beyond the Cloud: Anytime-anywhere learning in a smart campus environment," in IEEE International Conference Internet Technology and Secured Transactions (ICITST), Abu Dhabi, 2011, pp. 718-723.

[3] L. Badger, T. Grance, R. Patt-Corner and J. Voas, "Draft Cloud Computing Synopsis and Recommendations," In National Institute of Standards and Technology, Gaithersburg, Special Publication 800-146 2012. 
International Journal of Computer Science \& Engineering Survey (IJCSES) Vol.6, No.3, June 2015

[4] V. Andrikopoulos, S. Strauch and F. Leymann, "Decision Support for Application Migration to the Cloud: Challenges and Vision," in 3rd International Conference on Cloud Computing and Service Science (CLOSER'13), Aachen, 2013, pp. 149-155.

[5] G. Avram, "Advantages and Challenges of Adopting Cloud Computing from an Enterprise Perspective," in Procedia Technology, $7^{\text {th }}$ International Conference Interdisciplinarity in Engineering, Tirgu Mures, 2013, pp. 529-534.

[6] S. Marston, Z. Li, , S. Bandyopadhyay, , J. Zhang, and A. Ghalsasi, "Cloud Computing the Business Perspective," in System Sciences (HICSS), 2011 44th Hawaii International Conference , Kauai, 2011, pp. 1 - 11.

[7] L. Jun and W. Jun, "Cloud Computing Based Solution to Decision Making," Procedia Engineering, vol. 15, no. 0, pp. 1822-1826, 2011.

[8] B. Sodhi and T. Prabhakar, "Assessing Platform Suitability for Achieving Quality ," in The $19^{\text {th }}$ IEEE Asia Pacific Software Engineering Conference (IEEE APSEC 2012), Hong Kong, 2012, pp. 760 -765 .

[9] Z. Song, "A Decision Support System for Application Migration to the Cloud," University of Stuttgart, Stuttgart, Master's Thesis 2013.

[10] S. Park, S. Ryoo, "An empirical investigation of end-users' switching toward cloud computing: A two factor theory perspective," Computers in Human Behavior, vol. 29, no. 1, pp. 160-170, January 2013.

[11] N. Sultan, "Cloud computing for education: A new dawn?," The Journal for Information Professionals, vol. 30, no. 2, pp. 109-116, April 2010.

[12] A. Khajeh-Hosseini, D. Greenwood \& I. Sommerville, "Cloud Migration: A Case Study of Migrating an Enterprise IT System to Iaas," in Cloud Computing (CLOUD), 2010 IEEE $3^{\text {rd }}$ International Conference, Miami, 2010, pp. 450 - 457.

[13] P. Beserra, A. Camara, R. Ximenes,A.Albuquerque, N. Mendonça, "Cloudstep: A step-by-step decision process to support legacy application migration to the cloud," in Maintenance and Evolution of Service-Oriented and Cloud-Based Systems (MESOCA), 2012 IEEE $6^{\text {th }}$ International Workshop , Trnto, 2012, pp. 7 - 16.

[14] C. Fehling, F. Leymann, S. Ruehl, M. Rudek, S. Verclas , "Service Migration Patterns--Decision Support and Best Practices for the Migration of Existing Service-Based Applications to Cloud Environments," in Service-Oriented Computing and Applications (SOCA), IEEE $6^{\text {th }}$ International Conference, Koloa, 2013, pp. 9 - 16.

[15] W. Zhou, B. Cui, Y. Wang, Q. Shi, S. Yokoi, "Exploration of Public Education Resource Sharing and Cloud Services," in Computer Science \& Education (ICCSE), $8^{\text {th }}$ International Conference, Colombo, 2013 , pp. $1277-1280$.

[16] F. Ming-ming, Z. Le-hua ; W. Cong, W. Wei-hong, "Research on Distance Education System Based on Cloud Computing," in Computer Science \& Service System (CSSS), International Conference, Nanjing, 2012, pp. 1639 - 1642.

[17] C. Li, R. Dutta, C. Kloppers, C. D'Este, A. Morshed, A. Almeida, and J. Aryal, "Mobile Application Based Sustainable Irrigation Water Usage Decision Support System: An Intelligent Sensor CLOUD Approach" in SENSORS, IEEE, Baltimore, 2013, pp. 1 - 4.

[18] S. Miah and R. Ahamed, "A Cloud-Based DSS Model for Driver Safety and Monitoring on Australian Roads," International Journal of Emerging Sciences, vol. 1, no. 4, pp. 634-648, December 2011.

[19] A. Sun, "Enabling collaborative decision-making in watershed management using cloud-computing services," Environmental Modelling \& Software, vol. 41, pp. 93-97, March 2013.

[20] N. Sultan, "Making use of cloud computing for healthcare provision: Opportunities and challenges," International Journal of Information Management: The Journal for Information Professionals, vol. 34, no. 2, pp. 177-184, April 2014.

[21] X. Tan, Y. Kim, "Cloud Computing for Education: A Case of Using Google Docs in MBA Group Projects," in Business Computing and Global Informatization (BCGIN), International Conference, Shanghai, 2011 , pp. 641-644.

[22] M. Xiu, "Decision Support for Different Migration Types of Applications to the Cloud," University of Stuttgart, Stuttgart, Master's Thesis 2013.

[23] C. Kalloniatisa, H. Mouratidisb, M. Vassilisa, S. Islamb, S. Gritzalisc, E. Kavakli, "Towards the design of secure and privacy-oriented information systems in the cloud: Identifying the major concepts," Computer Standards \& Interfaces, vol. 36, no. 4, pp. 759-775, June 2014.

[24] W. Brisken and J. Romney, "To Lease Or Not To Lease From Storage Clouds," Computer, vol. 43, no. 4, pp. 44 - 50 , April 2010. 
International Journal of Computer Science \& Engineering Survey (IJCSES) Vol.6, No.3, June 2015

[25] M. Zhang, R. Ranjan, A. Haller,D. Georgakopoulos, P. Strazdins, "Investigating Decision Support Techniques for Automating Cloud Service Selection," in Cloud Computing Technology and Science (CloudCom), IEEE 4th International Conference, Taipei, 2012 , pp. 759 - 764.

[26] H. Mouratidisa, S.1 Islama, C. Kalloniatisb, S. Gritzalis, "A framework to support selection of cloud providers based on security and privacy requirements," Journal of Systems and Software, vol. 86, no. 9, pp. 2276-2293, September 2013.

[27] H. Demirkan, D. Delen, "Leveraging the capabilities of service-oriented decision support systems: Putting analytics and big data in cloud," Decision Support Systems, vol. 55, no. 1, pp. 412-421, April 2013.

[28] A. Khajeh-Hosseini, D. Greenwood, J. W. Smith, I. Sommerville, "The Cloud Adoption Toolkit: Supporting Cloud Adoption Decisions in the Enterprise," Software-Practice \& Experience, vol. 42 , no. 4, pp. 447-465, April 2012.

[29] A. Khajeh-Hosseini, I. Sommerville, J. Bogaerts, P. Teregowda, "Decision Support Tools for Cloud Migration in the Enterprise," in Cloud Computing (CLOUD), IEEE International Conference, Washington, 2011, pp. $541-548$.

[30] A. Juan-Verdejo, "Assisted migration of enterprise applications to the Cloud - A hybrid Cloud approach," in Tagungsband des 4. Workshops "Business Intelligence”, Mainz, 2012, pp. 14-27.

[31] M. Menzel, R. Ranjan, "Cloud Genius: Decision Support for Web Server Cloud Migration," in Proceedings of the 21st international conference on World Wide Web, New York, 2012, pp. 979-988.

[32] O. Khozaimya, A. Al-Dhaherib, A. Sharif Ullah, "A Decision-Making Approach Using Point-CloudBased Granular Information," Applied Soft Computing, vol. 11, no. 2, pp. 2576-2586, March 2011.

[33] S. Misra, A. Mondal1, "Identification of a Company's Suitability for the Adoption of Cloud Computing and Modelling its Corresponding Return on Investment," Mathematical and Computer Modelling, vol. 53, no. 3-4, pp. 504-521, February 2011

[34] S. Matoon,J. Baty, B. Hensle, C. Boot, "A Pragmatic Approach to Cloud Adoption," Oracle, Practitioner Guide Release 3.0, 2012.

[35] M. Mithani, M. Salsburg, S. Rao, "A Decision Support System for Moving Workloads to Public Clouds," GSTF INTERNATIONAL JOURNAL ON COMPUTING, vol. 1, no. 1, pp. 150-157, August 2010.

[36] T. Zandvliet, "A Decision Support Tool for Allocating SAP Application Data," Delft University of Technology, Delft, Master's Thesis 2013.

[37] Amazon Web Services. (2014, April 28).Education [Online]. Available: http://aws.amazon.com/education/

[38] Microsoft Corporation. (2014, April 28). Education [Online]. Available: http://www.microsoft.com/education/ww/products/Pages/Products.aspx

[39] IBM Cloud Academy. (2015, May 9). A collaborative community of leaders: Cloud Computing in Education [Online]. Available: http://www.ibm.com/solutions/education/cloudacademy/us/en/

[40] N.Cenka , B. Anggun and A.Hasibuan, "Enhancing educational services using cloud technology," in Information and Communication Technology (ICoICT), International Conference, Bandung, 2013, pp. $155-160$.

[41] M. Alabbadi, "Cloud Computing for Education and Learning: Education and Learning as a Service (ELaaS)," in Interactive Collaborative Learning (ICL), $14^{\text {th }}$ International Conference , Piestany, 2011, pp. 589-594.

[42] B.Akhmetov \& N. Izbassova, "Developing and customizing university business intelligence cloud," in Cloud Computing Technologies, Applications and Management (ICCCTAM), International Conference, Dubai, 2012 , pp. 229 - 233.

[43] Saudi Embassy. (2014, June 9). About Saudi Arabia [Online]. Available: http://www.saudiembassy.net/about/country-information/education/

[44] The Saudi Arabian Cultural Mission to the US. (2015, Febreuary 12).Background Educational System in Saudi Arabia [Online]. Available: http://www.sacm.org/Education.aspx

[45] F.Al-Fahad, "Students' Attitudes and Perceptions Towards the Effectiveness of Mobile Learning in King Said University," Turkish Online Journal of Educational Technology, vol. 8, no. 2, pp. 111-119, April 2009.

[46] Y. Alshumaim, R. Alhassan, "Current availability and use of ICT among Secondary EFL Teachers in Saudi Arabia," in Global Learn Asia Pacific - Global Conference on Learning and Technology, Penang, 2010, pp. 523-532.

[47] T. Altameem, "Contextual mobile learning system for Saudi Arabian Universities," International Journal of Computer Applications, vol. 21, no. 4, pp. 21-26, may 2011. 
International Journal of Computer Science \& Engineering Survey (IJCSES) Vol.6, No.3, June 2015

[48] A. Nassuora, "Students acceptance of Mobile Learning for Higher Education in Saudi Arabia," American Academic \& Scholarly Research Journal, vol. 4, no. 2, pp. 24-30, december 2012.

[49] H. Al-Bahadili, G. Issa and M. Abuhamdeh, "A hierarchical framework for evaluating success factors of M-learning," The Research Bulletin of Jordan ACM, vol. 2, no. 3, pp. 53 - 59, June 2011.

[50] H. Al-Bahadili, M. Abuhamdeh and G. Issa, "A scalable framework to quantitatively evaluate success factors of mobile learning systems," International Journal of Mobile Learning and Organisation, vol. 5, no. 3-4, pp. 299-316, February 2011.

[51] N. RadhaKrishnan, N. Chelvan, and D. Ramkumar, "Utilization of Cloud Computing in E-learning systems " in Cloud Computing Technologies, Applications and Management (ICCCTAM), International Conference, Dubai, 2012, pp. 208-213. 